\title{
Geomorfología del abanico proluvial La Yesera que está ocupada en parte por la localidad de San José Los Molinos, Ica-Perú
}

\begin{abstract}
RESUMEN
Geomorfológicamente, el torrente La Yesera es una unidad del relieve que se caracteriza por la ocurrencia de movimientos en masa profundos debido a que en su cuenca de recepción ocurren intensos procesos de meteorización y erosión.

Geológicamente, la cuenca de recepción de la referida unidad es un batolito con rocas deformadas por fracturas y fallas. El canal de desagüe y abanico del torrente está cubierto de potentes capas de lodo (arenas) y bloques (clastos y bolos). El abanico proluvial del torrente está muy disectado debido al impactado y la acción cortante de aluviones (huaycos) durante el cuaternario reciente (últimos 10,000 años).

El mencionado abanico proluvial se localiza aledaño al río Ica, por su margen izquierda. La vía asfaltada que une la localidad de San José Los Molinos con la ciudad de Ica corta el mencionado abanico en dos sectores. El primero contiguo al río Ica que está ocupado por terrenos de cultivos y algunas viviendas. En el segundo sector se localiza la localidad de San José Los Molinos que se encuentra expuesta al impacto de aluviones siendo un espacio de riesgos de desastres.
\end{abstract}

Palabras Clave: Abanico proluvial, torrente, aluviones, peligros de origen natural

\section{Geomorphology of the La Yesera proluvial fan that is partly occupied by the town of San José Los Molinos, Ica-Peru}

\begin{abstract}
Geomorphologically, the La Yesera torrent is a unit of the relief that is characterized by the occurrence of deep mass movements because intense weathering and erosion processes occur in its reception basin.

Geologically, the reception basin of the said unit is a batolith with rocks deformed by fractures and failures. The drainage channel and fan of the torrent is covered with powerful layers of mud (sand) and blocks (clasts and bowling). The proluvial fan of the torrent is very dissected due to the impact and the sharp action of alluvium (huaycos) during the recent quaternary (last 10,000 years). The aforementioned proluvial fan is located adjacent to the Ica River, on its left bank. The paved road that connects the town of San José Los Molinos with the city of Ica cuts the aforementioned range into two sectors. The first is adjacent to the Ica River that is occupied by farmland and some homes. In the second sector is located the town of San José Los Molinos that is exposed to the impact of floods being a disaster risk space.
\end{abstract}

KEYwORD: Proluvial fan, torrent, floods, hazards of natural origin 


\section{Introducción}

\section{Área de estudio}

$\mathbf{E}$ área de estudio comprende el torrente de La Yesera, unidad geomorfológica donde se desarrollan procesos de movimientos en masa profundo (deslizamientos, aluviones y caídas).

El abanico proluvial es la geoforma donde ocurren los mayores impactos por los aluviones y a su vez el espacio natural de acumulación.

\section{Localización}

El torrente La Yesera, cuyo abanico proluvial en parte está ocupado por el asentamiento humano San José Los Molinos, se localiza a unos $20 \mathrm{~km}$ al Noreste de la ciudad de Ica. Asimismo, la referida localidad es capital del distrito del mismo nombre, provincia Ica, departamento Ica. En el Anexo 1 se puede observar la localización del torrente La Yesera.

\section{Problema}

\section{Descripción de la realidad problemática}

Geográficamente, el territorio está conformado por una diversidad de asentamientos humanos que tienen como centro financiero, comercial y de servicios a la ciudad de Ica. El impacto de actividades económicas como la agroindustria, turismo, así como los servicios que brinda la ciudad de Ica, por consiguiente, se proyecta en el espacio con la aparición de nuevos asentamientos humanos a manera de expansión de antiguos centros poblados. Uno de esos asentamientos humanos es San José Los Molinos que en los últimos 10 años se ha incrementado la construcción de viviendas. Por lo tanto, la sociedad ha creado un escenario de riesgos de desastres.

Se trata de procesos sociales y económicos que generan un patrón de ocupación territorial. En muchos casos el acelerado proceso de urbanización y la ocupación informal se realiza sobre zonas que pueden ser impactadas por fenómenos de origen natural como deslizamientos, aluviones (huaycos), caídas, así como, inundaciones debido crecidas de ríos. Las menciona- das actividades económicas se desarrollan sobre geoformas como por ejemplo las terrazas inundables del río Ica y los abanicos y terrazas proluviales (torrentes).

La localidad de San José Los Molinos se localiza sobre el abanico proluvial La Yesera, geoforma que ha sido impactado por aluviones durante el cuaternario reciente (últimos 10,000 años). En el Anexo 2 se visualiza el torrente La Yesera.

En suma, esa conjunción de procesos sociales y naturales ha determinado escenarios de riesgos, un caso típico es la localidad de San José Los Molinos. La mencionada localidad tiene antecedentes de haber sido impactados por movimientos en masa, por ejemplo, el aluvión de 1998.

La gestión de riesgos para estos espacios locales consiste en una primera etapa en disponer de estudios de riesgos actualizados al menos cada 2 años. En una segunda etapa los resultados del citado estudio deberá ser la base para elaborar una propuesta de gestión e riesgos que el marco del ordenamiento territorial.

Por lo tanto, un estudio geomorfológico permite el conocimiento de los mencionados procesos naturales y favorece la identificación de los peligros de origen natural. Cabe agregar, que el uso de las herramientas de la geomática y de los Sistemas de Información Geográfica coadyuva en el análisis de la geomorfología. Este trabajo aporta con el conocimiento de una parte de la referida problemática poniendo a disposición información a escala grande de mapas sobre la geomorfología de la mencionada área de estudio.

\section{Objetivo general}

Conocer la geomorfología del abanico proluvial de La Yesera que en parte está ocupada por la localidad de San José Los Molinos, Ica.

\section{Objetivos específicos}

- Analizar la geomorfología del abanico proluvial del torrente La Yesera.

- Estudiar la morfogénesis de las geoformas derivadas de los movimientos en masa en el torrente de La Yesera.

- Preparar un mapa geomorfológico del aludido abanico proluvial a escala grande utilizando una clasificación geomorfológica por elementos. 


\section{Desarrollo del trabajo}

\subsection{Geología}

\section{Geología histórica}

La localización del Perú en el denominado Cinturón de Fuego de Pacífico se vincula con la formación de la Cordillera de los Andes sobre todo por subducción de las placas Nazca y Sudamericana. Al ser una cordillera geológicamente joven, por consiguiente, los eventos tectónicos y erosivos son intensos.

Los eventos tectónicos cercanos al área de estudio tal como el levantamiento de las terrazas marinas durante el cuaternario pleistocenico, así como, la depresión tectónica Ica-Nazca. Este último localizado paralelo a la costa entre la planicie costera y el piedemonte del flanco andino Occidental. De otra parte, los abanicos aluviales que cortan el mencionado piedemonte. En suma, a nivel regional esos eventos caracterizan la geología y geomorfología de los espacios aledańos al área de estudio.

El Batolito de la Costa del cretáceo superior aflora en gran parte del torrente La Yesera sobre todo en la cuenca de recepción, a su vez deformada por fallas.

\section{Geología local}

La geología local está constituida por un batolito en gran parte del torrente sobre todo en su cuenca de recepción. En laderas aledañas al abanico proluvial afloran las rocas volcano-sedimentarias del Grupo Quilmana. En el canal del torrente y en el abanico

\begin{tabular}{|c|c|c|c|}
\hline Nro. & \begin{tabular}{|l|} 
Nombre de la \\
unidad geológica
\end{tabular} & Símbolo & Descripción litológica \\
\hline 1 & $\begin{array}{l}\text { Depósito } \\
\text { aluvial } 1\end{array}$ & Q-al1 & $\begin{array}{l}\text { Conglomerados } \\
\text { polimétricos envueltos } \\
\text { en una matriz arena } \\
\text { conglomeradita. }\end{array}$ \\
\hline 2 & $\begin{array}{l}\text { Depósito } \\
\text { aluvial } 2\end{array}$ & Q-al2 & $\begin{array}{l}\text { Abanicos aluviales } \\
\text { compuestos de bolos, } \\
\text { gravas, arenas y limos. }\end{array}$ \\
\hline 3 & $\begin{array}{l}\text { Grupo } \\
\text { Quilmana }\end{array}$ & Kis-q & $\begin{array}{l}\text { Volcánicos con } \\
\text { intercalaciones de calizas. }\end{array}$ \\
\hline 4 & $\begin{array}{l}\text { Superunidad } \\
\text { Linga } \\
\end{array}$ & $\begin{array}{l}\mathrm{Ki}-\mathrm{li} / \mathrm{qmz}- \\
\mathrm{mzdi}\end{array}$ & $\begin{array}{l}\text { Rocas intrusivas } \\
\text { monzograbo, monzodiorita. }\end{array}$ \\
\hline 5 & $\begin{array}{l}\text { Superunidad } \\
\text { Patap }\end{array}$ & $\mathrm{Ki}-\mathrm{pt} / \mathrm{gb}$ & $\begin{array}{l}\text { Roca intrusiva } \\
\text { gabrodiorita. }\end{array}$ \\
\hline 6 & $\begin{array}{l}\text { Superunidad } \\
\text { Pampahuasi }\end{array}$ & Ks-pa/to & Roca intrusiva, tonalita. \\
\hline
\end{tabular}

Fuente: INGEMMET esta rellenado por arenas, clastos y bolos. La mencionada litología se visualiza en el mapa geológico (Anexo 3). La información litológica se ha obtenido descargando del geoservidor GEOCATMIN de INGEMMET.

La litología del torrente se resume el cuadro anterior.

\subsection{Geomorfología}

\subsubsection{Geomorfología}

\section{Geomorfología regional}

La geomorfología está caracterizada por dos grandes unidades: el Flanco Andino Occidental y su piedemonte denominado también como estribaciones andinas. Las quebradas que cortan las montañas del Flanco Andino Occidental, sobre todo las de corto recorrido geomorfológicamente conforman torrentes. Por último, se encuentra la unidad de valle inundable del río Ica.

\section{Geomorfología local}

La geomorfología local comprende el torrente de La Yesera, que está dividido en tres partes: cuenca de recepción, canal de desagüe y abanico o cono deyectivo. Cabe precisar, que para el caso del abanico del área de estudio se ha señalado el nombre abanico proluvial por tratarse de un torrente que proviene de las montańas y que desemboca en un valle (río Ica).

\subsubsection{Mapas geomorfológicos y de pendientes}

\section{Mapa geomorfológico del torrente de La Yesera}

Se ha elaborado un mapa geomorfológico del torrente La Yesera que se observar en el Anexo 4. El referido mapa contiene las siguientes unidades geomorfológicas:

a. Montañas de rocas intrusivas (Mo-Ri). La cuenca de recepción está compuesta de montańas de roca intrusiva con laderas escarpadas o de fuertes pendientes deformada por fracturas y fallas. El canal de desagüe disecta las montańas de roca intrusiva donde se originan los movimientos en masa profundo como aluviones (profundizando el cauce) y caídas (determinando por procesos gravitatorios o coluviales a los taludes de derrubios). 
b. Colinas intrusivas (Co-Ri). Las colinas de rocas intrusiva comprenden geoformas de menos de 50 metros de altura se localizan aledaño al abanico proluvial del torrente. Las laderas de estas geoformas están muy meteorizadas y se encuentran disectadas por cárcavas que a su vez generan conos de derrubios.

c. Lomas (Lo). Es una geoforma de poca altura (menos de $25 \mathrm{~m}$ ) alargado disectada por cárcavas localizado aledaño al abanico proluvial de La Yesera.

d. Abanico proluvial (Ab). El abanico proluvial La Yesera debido a los procesos de erosión, aluviones, sobre todo, se encuentra densamente disectado cubierta con potentes capas de arenas y bolos. Un pequeño torrente conocido con el nombre de Mina hace confluencia con el abanico La Yesera, por esa razón conforman un gran abanico coalescente. Por consiguiente, el abanico proluvial de La Yesera es una geoforma coalescente muy disectado y muy dinámico en cuanto a la ocurrencia de aluviones.

e. Planicie aluvial (Pl-al). La planicie aluvial está conformada por una serie de terrazas aluviales del río Ica de poca altura (entre 5 a 10 metros) aledaño al abanico proluvial de La Yesera. Las mencionadas terrazas son difíciles de reconocer en el campo por las alteraciones que se han realizado por las actividades agrícolas y la infraestructura, como caminos y canales.

f. Valle inundable (Vi). El valle inundable comprende terrazas aluviales del río Ica de menos de 5 metros de altura que normalmente son impactados durante las crecidas del río Ica.

Mapa geomorfológico del abanico del torrente La Yesera Se ha preparado un mapa geomorfológico del abanico proluvial La Yesera de modo que se recogen las geoformas a escala 1: 5000 (ver Anexo 5). Se trata de un mapa geomorfológico por elementos porque se grafica a esa escala grande cada una de las geoformas. Mediante el referido mapa se va analizar no solo la morfología sino también la morfogénesis y la dinámica actual del área de estudio.

\section{Clasificación del mapa geomorfológico}

Jean Tricart, señaló que el carácter genético intrínseco de la geomorfología permite comprender como esta disciplina puede ser objeto de aplicaciones. Estas afirmaciones de Tricart sobre geomorfología aplicada nos ayuda a comprender como cada una de las aplicaciones corresponden a un objetivo general. De modo que se requiere una clasificación del relieve adaptado a cada realidad.

Una de esas aplicaciones es el tratamiento de los peligros de origen natural como por ejemplo los aluviones. A continuación, se presenta la clasificación del relieve que se ha elaborado sobre la base de los criterios de la geomorfología y adecuado a la realidad del caso.

\section{a. Formas de origen endógeno \\ - Colina de roca intrusiva}

Son geoformas de rocas intrusivas que se encuentran muy meteorizadas de ahí que vienen ocurriendo procesos gravitatorios o coluviales como deslizamientos y caídas originando microformas de taludes de derrubios.

En las laderas de las colinas aledaño a la zona de contacto entre el canal de desagüe y el abanico proluvial, se encuentran capas de loess. Los loess son sedimentos de limo de modo que corresponden a depósitos eólicos y de igual manera se trata de una microforma.

\section{b. Formas de origen exógeno \\ - Abanico proluvial}

El abanico está muy disectado por pequeñas quebradas, sin embargo, teniendo en cuenta la geomorfología las denominaremos "disecciones". Las mencionadas disecciones presentan profundidades o alturas entre 1 a 6 metros y con anchos entre 2 a $7 \mathrm{~m}$. Las mencionadas disecciones están graficadas como líneas. Asimismo, las disecciones del abanico son densas lo que indica lo cortante que son los procesos de aluviones. Las disecciones en número suman entre 12 a 15 considerando la parte central del abanico. Otro indicador de la ocurrencia de movimientos en masa profundo (aluviones) es la presencia de abundante material torrencial como bolos y los depósitos de arenas.

Se ha encontrado que el abanico del torrente La Yesera tiene tres sectores o áreas debido a su homogeneidad en cuanto a densidad de disección, profundidad y material superficial, que se describe a continuación. 
La parte del lado derecho del abanico La Yesera situado al Noreste de la localidad de San José Los Molinos. En ese tramo el aludido abanico recorre muy "pegado" a las colinas de rocas intrusivas a su vez "rodeándolo" generando un sub-abanico muy bien formado debido a que está muy disectado. En las fotografías del Anexo 7 se visualiza el referido tramo.

La parte central del abanico proluvial la Yesera está igualmente disectado y colmatado por arenas, clastos, bloques y bolos. En ese sector del abanico se encuentran las disecciones de mayor profundidad entre 3 a 6 metros.

En el lado izquierdo del abanico La Yesera confluye con otro torrente señalado con el nombre de Mina, generándose de esa manera un abanico proluvial coalescente. Aledaño a este espacio se encuentra una loma de roca intrusiva.

En consecuencia, las aludidas disecciones atraviesan el asentamiento humano San José Los Molinos y en el paisaje urbano se encuentran a manera de "calles" por donde se puede detectar bolos de diámetros de 3 a 5 metros. La ocurrencia de eventuales aluviones se efectúan sobre esas disecciones y al ser cortantes generan nuevas "disecciones" y dependiendo de su intensidad pueden llegar hasta el cauce del río Ica.

- Campo de bolos

Son espacios del abanico proluvial caracterizado por estar cubierto de potentes depósitos de arenas y bolos. Es otro indicador de la ocurrencia de movimientos en masa profundos.

- Cárcavas

Las cárcavas son geoformas originadas por la erosión hídrica y sobre todo por los deslizamientos que van profundizando su cauce. Esas cárcavas se encuentran disectando colinas de roca intrusiva e indica antiguos climas donde ocurrían fuertes precipitaciones.

- Planicie aluvial

Esta geoforma comprende un conjunto de terrazas aluviales de poca altura y bajos declives. Actualmente se encuentra muy alteradas por actividades agrícolas.

c. Formas construidas por el hombre (Antrópico) Estas formas son construcciones humanas como las carreteras, canales de acequias y terrazas agrícolas.

En el Anexo 7 se observan fotografías de las geoformas del mapa geomorfológico.

\section{Mapa de pendientes del terreno (declives)}

Las geoformas del torrente La Yesera analizadas arriba tienen características topográficas y geométricas que fueron identificadas en gabinete y reconocidas en el campo para facilitar su análisis desde el punto de vista morfogénetico. Para este fin previamente se construyó un Modelo de elevación del terreno mediante el empleo de las herramientas de la geomática. El procedimiento para obtener insumos topográficos fueron los siguientes:

Imágenes de radar ALOS PALSAR obteniendo un DEM de 12. 5 metros de resolución. Se preparó un mapa topográfico con curvas cada 5 metros para facilitar la identificación de las geoformas y su altura.

Pendientes del terreno. Las pendientes del terreno es otro de los insumos que se necesita para estudiar la geomorfología de un área de interés. Se utilizó la siguiente clasificación de rangos de pendientes y colores: $>50^{\circ}$ (rojo), $50^{\circ}-35^{\circ}$ (rosado), $35^{\circ}-15^{\circ}$ (anaranjado), $15^{\circ}-5^{\circ}$ (amarillo) y $<5^{\circ}$ (verde). El mapa de pendientes (Ver Anexo Nro. 6) se relaciona con algunas geoformas, por ejemplo, los rangos $>50^{\circ}$ y $50^{\circ}$ $35^{\circ}$ con las montañas, $35^{\circ}-15^{\circ}$ con colinas, mientras los rangos $15^{\circ}-5^{\circ}$ con conos y taludes de derrubios y $<5^{\circ}$ con el abanico proluvial, así como, sus microformas como las disecciones y bolos.

\section{Análisis de resultados}

La morfogénesis es muy importante para la gemorfología porque estudia el origen de las geoformas y desde allí debe partir cualquier análisis geomorfológico. Como se mencionó anteriormente las rocas de cuenca de recepción del torrente La Yesera está muy fracturada, el canal de desagüe se encuentra colmatado por estratos de arena y bolos. Por esos motivos se evidencia en el terreno una serie de aluviones que se han desarrollado durante el cuaternario reciente. De otra parte, el abanico proluvial se encuentra muy disectado por los mencionados movimientos en masa. En las laderas de las colinas y montańa aledañas al abanico están muy meteorizadas y en consecuencia muy disectadas por cárcavas.

Es decir, las condiciones geológico geomorfológico del basamento rocoso y los mantos de derrubios en las laderas han sufrido intensos procesos de meteorización y erosión, sumados a los efectos de los 
movimientos neotectónicos y los sismos. A todo ello se agrega el clima semi-árido sobre todo en la cuenca de recepción del torrente y las anomalías termo-oceánicas (El Niño) que ocasionan lluvias esporádicas pero intensas. Por lo tanto, el origen de los aluviones es muy complejo, en consiguiente se relacionan con la conjunción de factores geológicos, geomorfológicos y climáticos.

\section{Conclusiones}

1. La geomorfología del abanico proluvial del torrente La Yesera está determinada por los movimientos en masa profundo como los aluviones (huaycos), en consecuencia, originan acciones cortantes (erosión) y acumulación violenta de material superficial sobre el terreno.

2. La morfogénesis del torrente de La Yesera está vinculada a los procesos tectónicos y de erosión que han ocurrido durante las edades el Terciario y Cuaternario, es decir como parte de la evolución de la Cordillera de los Andes. Asimismo, el Batolito es el basamento sobre la cual se originó el torrente La Yesera.

3. El mapa geomorfológico del aludido abanico proluvial, a escala grande, facilito el análisis de la geomorfología, identificando tres sectores delimitados por la densidad de disección y profundidad de erosión. Normalmente, en todos esos espacios se producen acciones de movimientos en masa profundo.

4. El asentamiento humano de San José los Molinos (Ica) se encuentra expuesto al impacto de los aluviones porque sus construcciones se encuentran aledańos a las disecciones del abanico.

5. En años recientes la construcción de diques y caminos han alterado la geometría natural de las disecciones del abanico dificultando el estudio morfogénetico y morfométrico.

\section{Referencias bibliográficas}

Carenas, María; Giner, Jorge (2014). Geología. Madrid: Lavel Industria Gráfica

Dávila, Jorge (2011). Diccionario geológico. Lima.

De Pedraza, Javier (1996). Geomorfología - Principios, métodos y aplicaciones. Madrid: Editorial Rueda.

INGEMMET (1993). Boletin No 47 Geología de los cuadrangulos de Pisco, Guadalupe, Punta Grande, Ica y Cordova.

Lugo Hup, José (2011). Diccionario geomorfológico. México: UNAM. 


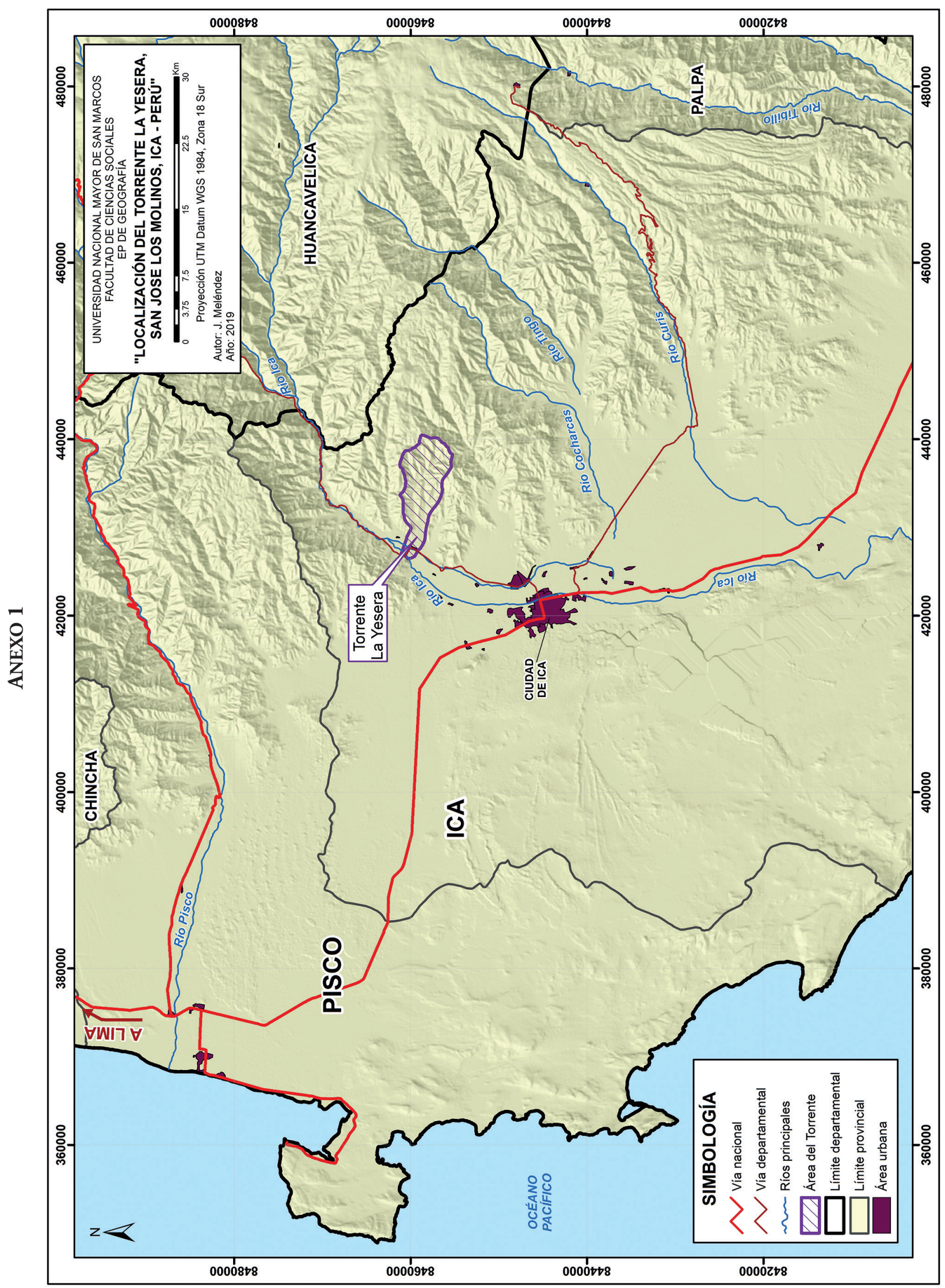




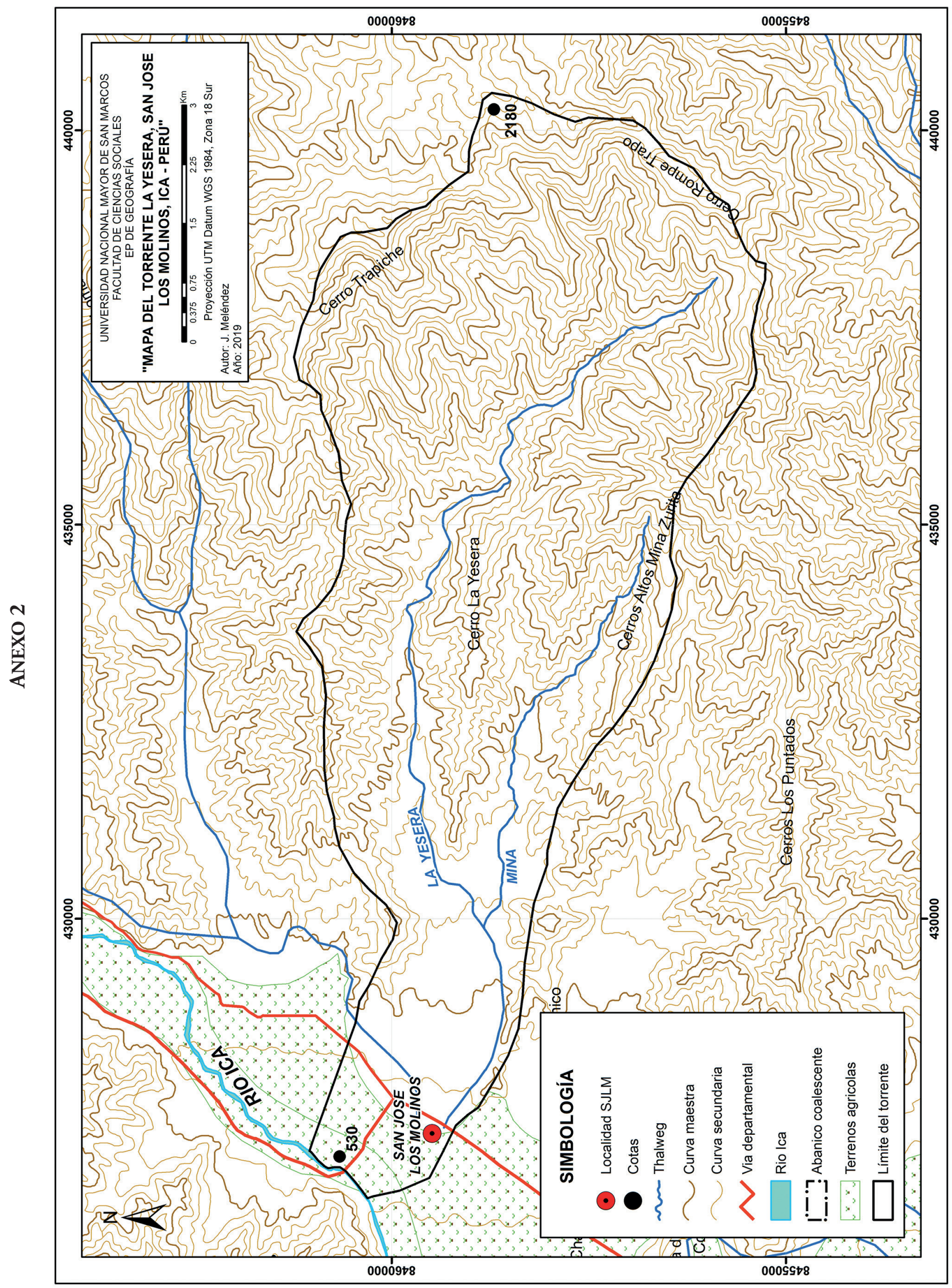




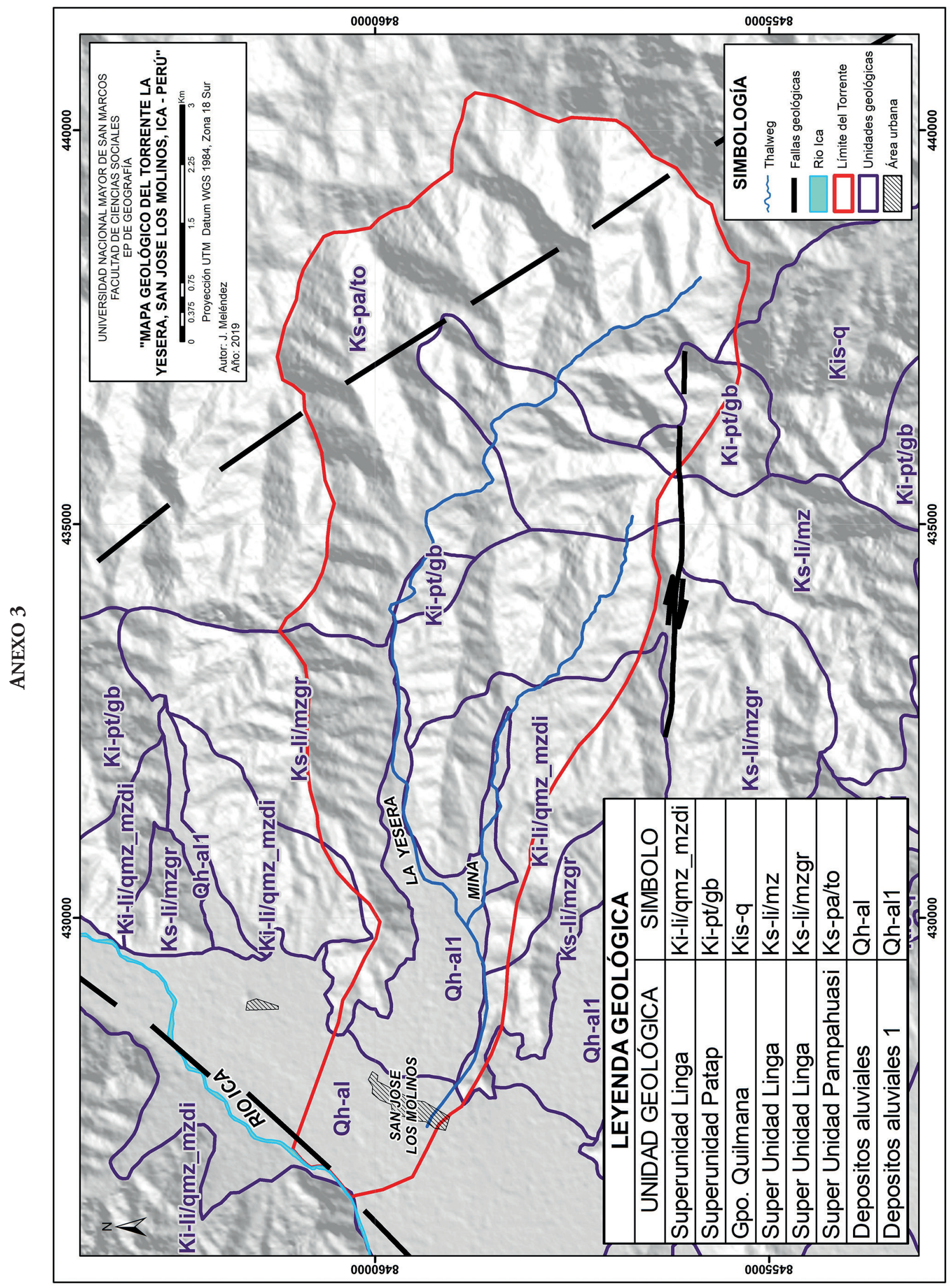

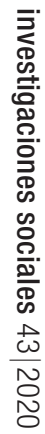




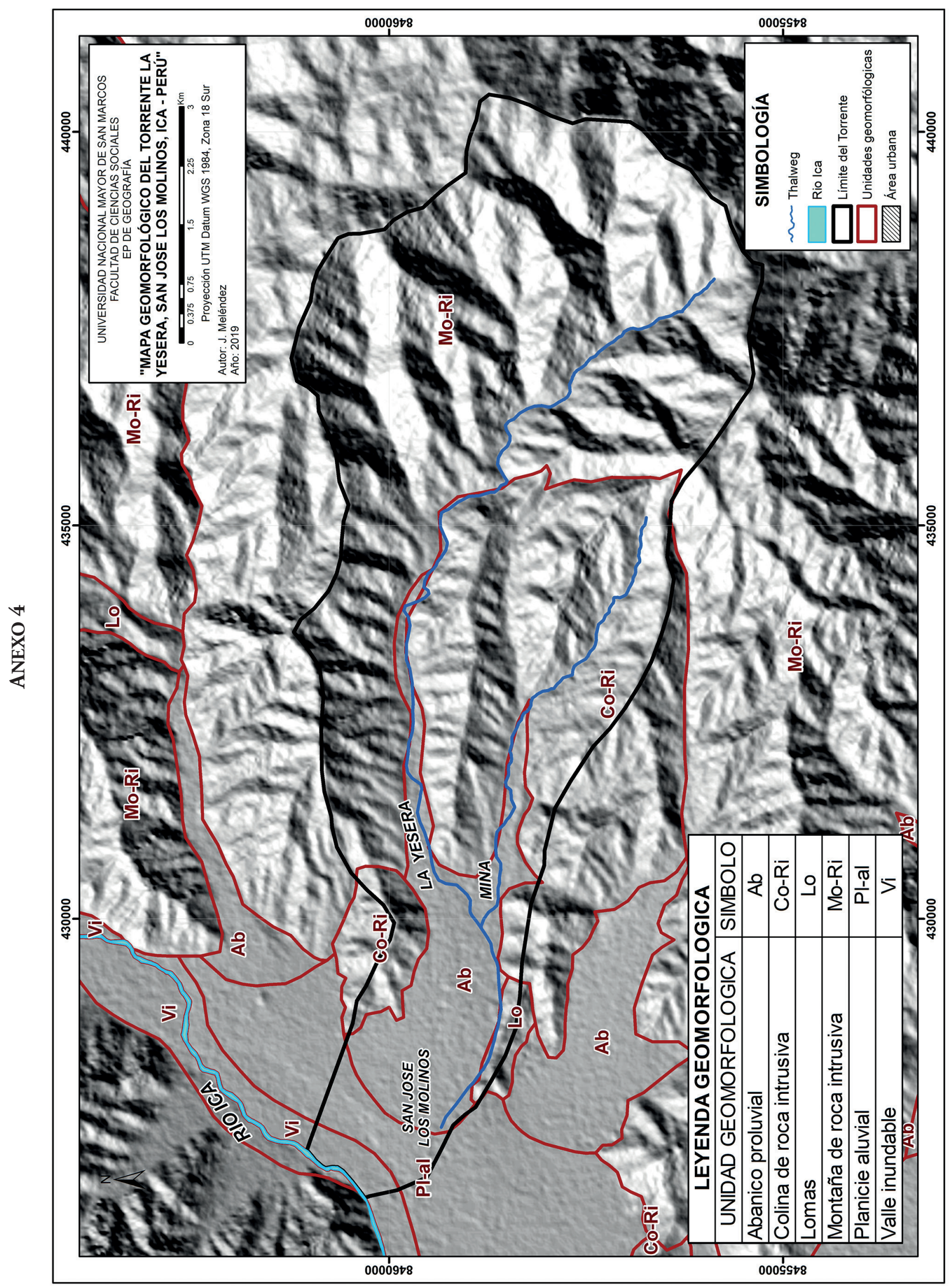




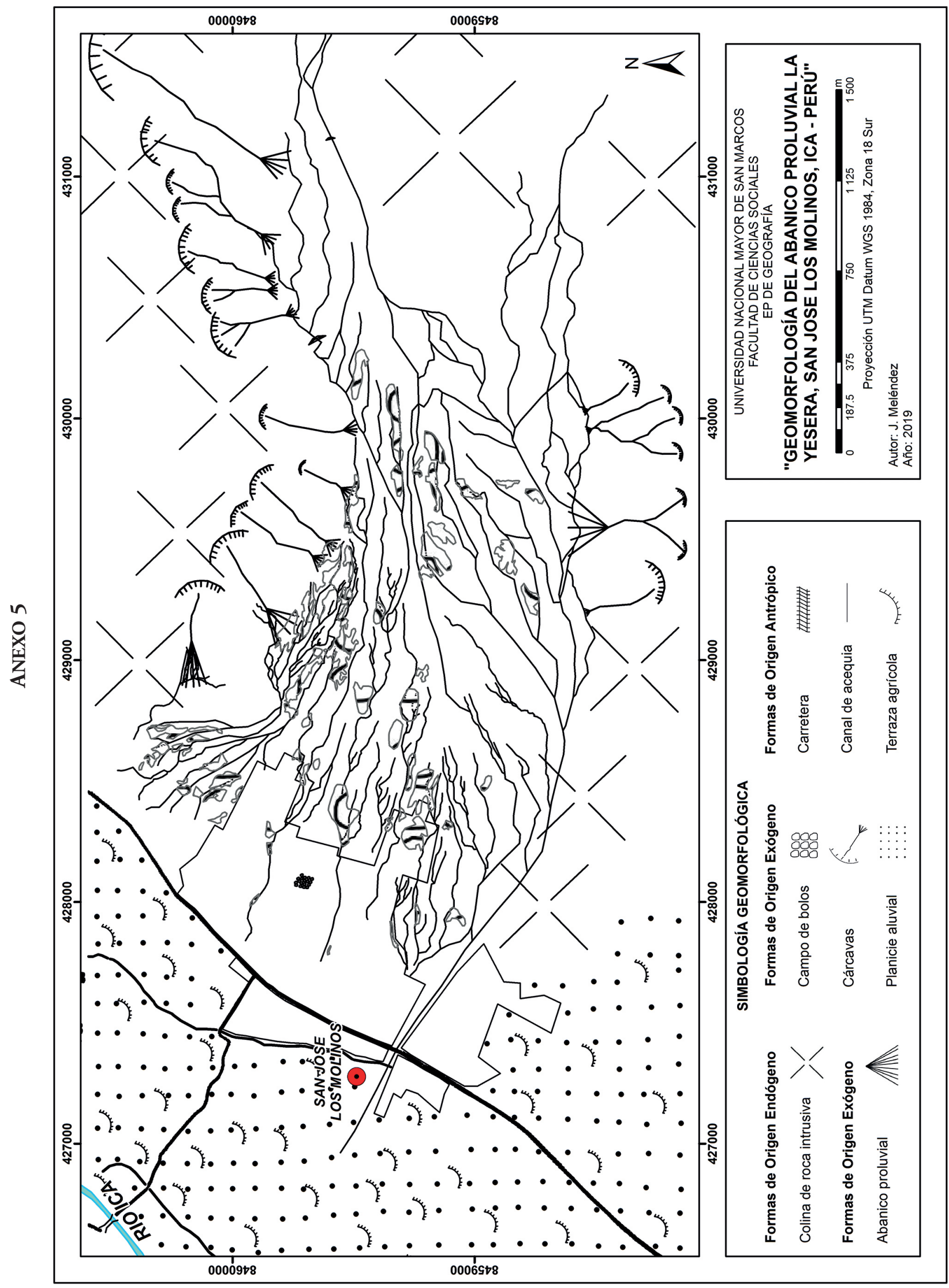




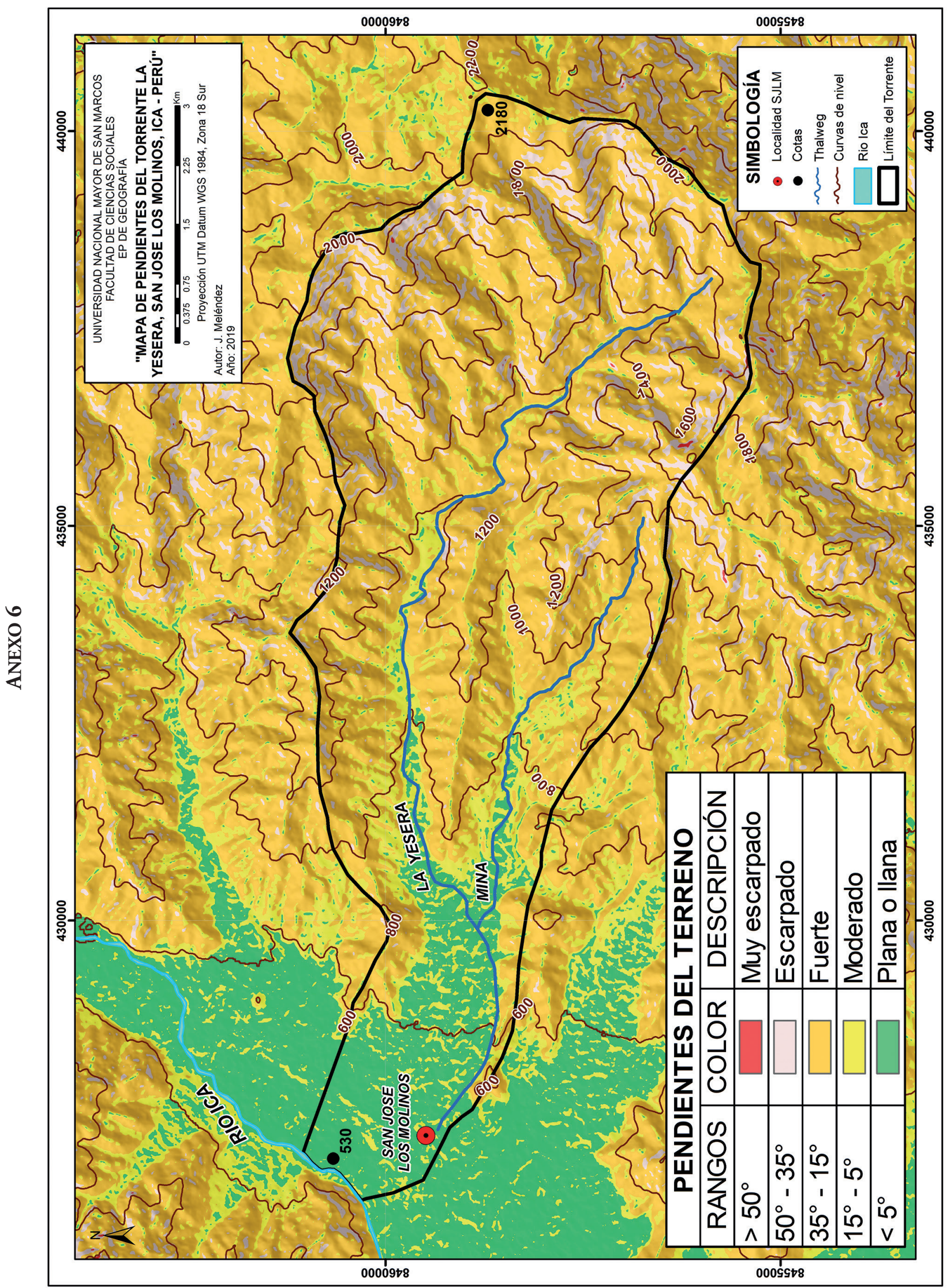




\section{ANEXO 7 - Fotografías}
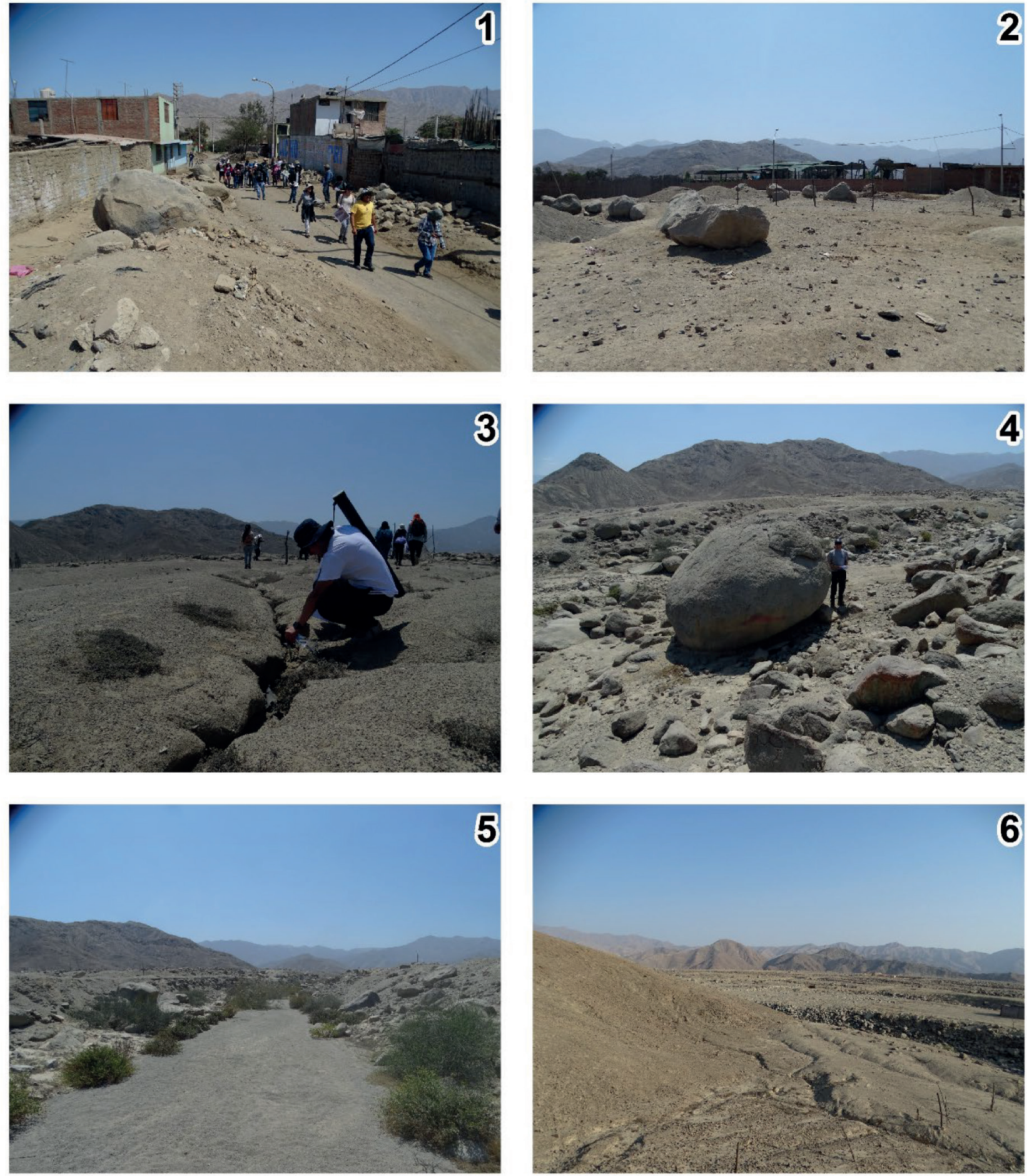

1. Una de las disecciones del abanico La Yesera que a su vez es una calle de San José Los Molinos (Ica). 2. Geoforma "Campo de bolos". 3. Es una muestra de una disección con escasa profundidad originada por la erosión intensa. 4. Se visualiza una disección y material superficial (bolos, clastos y arenas). También se observan las colinas de rocas intrusivas, 5 . Ejemplo de una disección que se encuentra colmatado. 6. Se visualiza el sub-abanico La Yesera muy disectado. 